\title{
Disseminated coccidioidomycosis with molluscum- like lesions, diffuse lymphadenopathy, and splenomegaly in an immunocompetent patient
}

This article was published in the following Dove Press journal:

International Medical Case Reports Journal

20 July 2017

Number of times this article has been viewed

\author{
Ernest Fonocho' \\ Richard Murray ${ }^{2}$ \\ Nail Aydin' \\ 'Texas Tech University Health \\ Sciences Center, ${ }^{2}$ Department \\ of Radiology, NorthWest Texas \\ Healthcare System, Amarillo, TX, USA
}

\begin{abstract}
Coccidioidomycosis is caused by a dimorphic fungus species endemic to the arid and semi-arid regions of the Americas. The species have a terranean habitat producing a primary pulmonary infection by inhalation of arthroconidia. We describe a case of extrapulmonary coccidioidomycosis presenting with extensive lymphadenopathy, splenomegaly, and florid cutaneous lesions. This case is intended to heighten clinical suspicion in patients with risk factors. Keywords: rare, manifestation, disease, florid, facial, papules
\end{abstract}

\section{Background}

Coccidioidomycotic infections can be asymptomatic or self-limited. Symptomatic infection most commonly presents as pneumonia, but lymphatic and hematogenous disseminations can produce extrapulmonary illness in $<5 \%$ of cases. ${ }^{1}$ Dissemination is most common to the skin, soft tissue, central nervous system, and bone. ${ }^{2}$ Immunosuppressed persons and individuals of African-American and Filipino descents are at a particularly high risk of disseminated disease. ${ }^{3}$

There are several diagnostic tests such as tissue analysis, tissue culture, and serology that can help in the diagnosis, among which tissue culture is the gold standard. ${ }^{3}$ Detection of coccidioidal antigens in the skin through delayed hypersensitivity is of limited clinical value due to its inability to distinguish active from prior infection. ${ }^{4}$

\section{Case presentation}

A 33-year-old otherwise healthy African-American male with an 8-year history of incarceration presented to a local emergency department with a 2-month history of fatigue and a 30-pound weight loss. He had fever, night sweats, chills, and decreased appetite during this period, with worsening of his symptoms in the days prior to presentation. Before presenting to our emergency department, he was treated empirically with Azithromycin for a bout of productive cough by an outside emergency department and he received empiric treatment for skin lesions presumptively diagnosed as molluscum contagiosum. He started a lawn-mowing job 2 months before presentation. He had never been out of Texas and had a past history of alcohol and tobacco use.

He appeared cachectic on presentation and had numerous cauliflower-like lesions on his face (Figure 1) and extensive adenopathy including the cervical, supraclavicular, axillary, and inguinal regions. There was radiologic evidence of extensive mediastinal and hilar adenopathy and splenomegaly measuring $14.0 \mathrm{~cm}$ on computed tomography (Figures 2 and 3). His presenting labs were unremarkable apart from a decline in
Correspondence: Ernest Fonocho Texas Tech University Health Sciences Center, I 400 S. Coulter St, Amarillo, TX 79106, USA

Email ernest.n.fonocho@ttuhsc.edu 


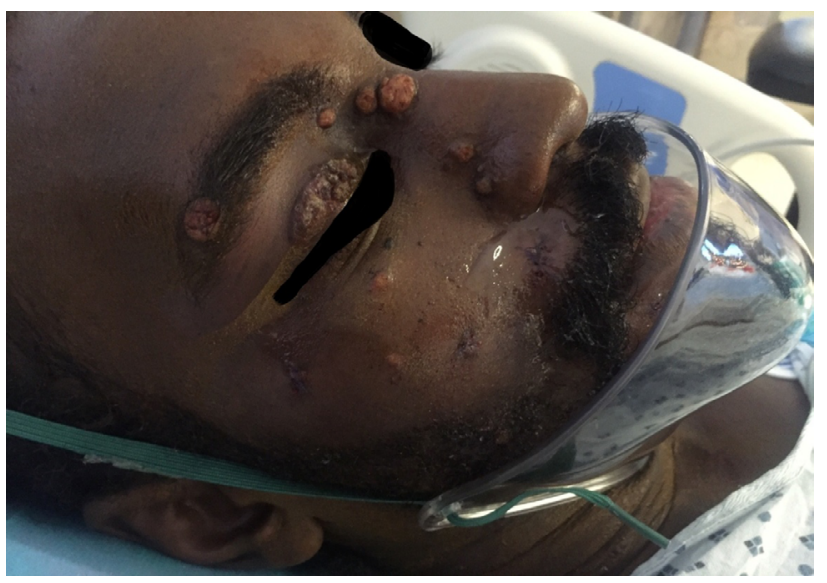

Figure I Photo of the patient showing the multiple cauliflower-like lesions.

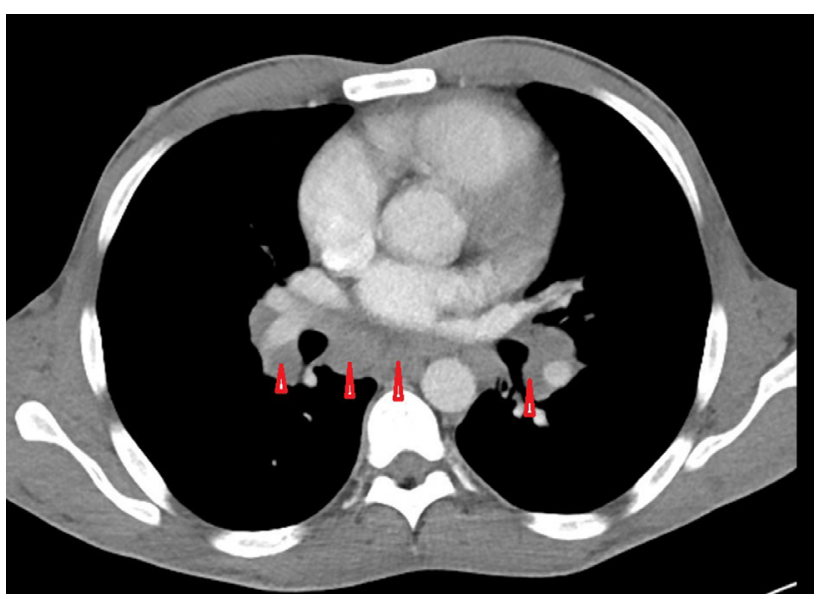

Figure 2 CT chest showing extensive hilar and mediastinal adenopathy (red arrow heads).

hemoglobin from $10.2 \mathrm{~g} / \mathrm{dL}$ to $7.8 \mathrm{~g} / \mathrm{dL}$ within the last month. An excisional biopsy of two right axillary lymph nodes was performed. Pathology of one node reported granulomatous inflammation with giant cell reaction and focal necrosis with fungal elements most compatible with Coccidioides species (Figure 4). Acid-fast stain to rule out Mycobacterium infection was negative and there was no evidence of malignancy. He was started on a prolonged course of 400 mg fluconazole daily, and he responded to treatment with regression of lesions.

\section{Discussion}

The coccidioidal species are endemic to the Western hemisphere, predominantly in southwestern regions of the USA and northern Mexico. ${ }^{5,6}$ In endemic areas of the USA, the overall incidence in 2011 was 42.6 cases per 100,000 and was highest among individuals $60-79$ years old $(69.1 / 100,000){ }^{7}$ Infection occurs upon inhalation of arthroconidia which germinate into spherules that later rupture to release endospores.

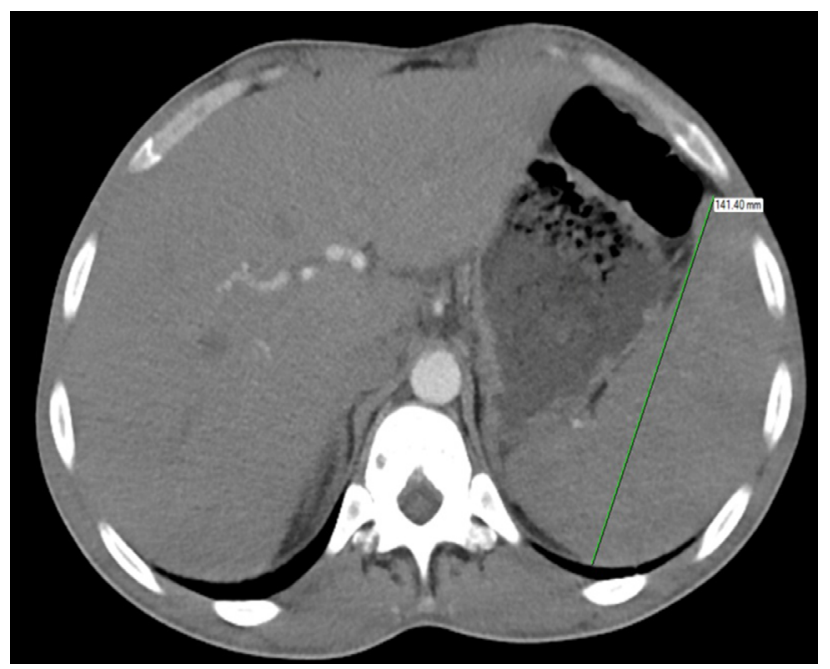

Figure 3 CT abdomen showing enlarged spleen measuring $14.1 \mathrm{~cm}$.

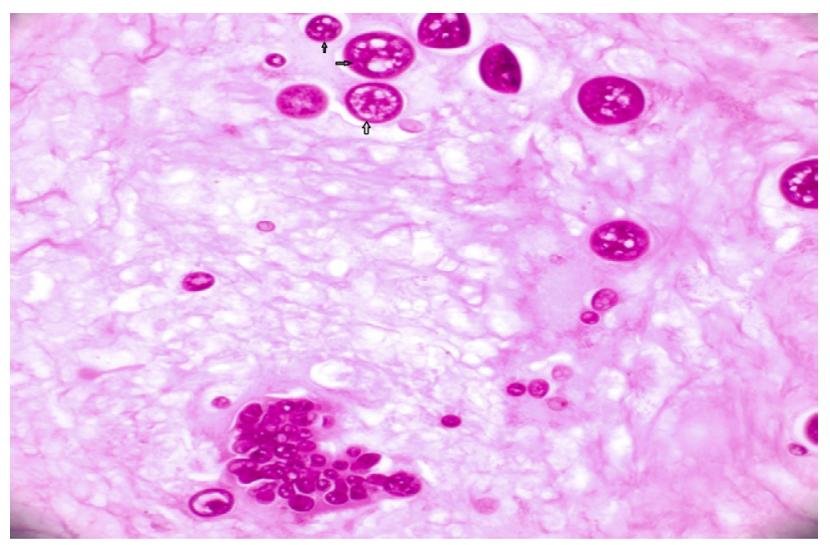

Figure 4 PAS stain showing multiple spherules with endospores (arrows).

Coccidioidal infection has five main clinical manifestations including acute pneumonia, chronic progressive pneumonia, pulmonary nodules and cavities, extrapulmonary nonmeningeal disease, and meningitis. ${ }^{2}$ Symptomatology ranges from mild to severe, with the latter defined by the need for hospitalization. ${ }^{8-10}$ Pulmonary involvement is most frequent and includes pneumonia, pleural effusion, hilar lymphadenopathy, and lung nodules. ${ }^{2}$ Acute respiratory infection occurs about 1-3 weeks postinhalation, manifesting with typical symptoms of community-acquired respiratory illness, such as fever, headache, productive cough, fatigue, and pleuritic chest pain, with increased severity of headache and pleuritic chest pain suggesting coccidioidal infection. ${ }^{1,11}$

As aforementioned, lymphohematogenous spread account for disseminated disease, occurring in $\sim 1 \%$ of cases, ${ }^{1,12}$ manifesting with systemic symptoms such as fever, cough, and night sweats. ${ }^{11}$ Coccidioidomycosis most commonly disseminates to the skin hematogenously, ${ }^{2,13}$ manifesting 
several weeks after the primary pulmonary infection ${ }^{12}$ as papules, nodules, verrucous plaques, pustules, and sinus tracts. ${ }^{13,14}$ Disseminated skin infection is typically nodular ${ }^{11}$ occurring on the face, neck, scalp, and chest wall, ${ }^{15,16}$ with the nasolabial folds being the most frequent location. ${ }^{13,17,18}$ Facial involvement has been linked to meningitis in some patients. ${ }^{19}$ Carpenter et al reviewed the clinical and pathologic aspects of disseminated coccidioidomycosis and observed protean and subtle manifestations. ${ }^{17}$ The wide range of disseminated cutaneous lesions warrants the consideration of a differential diagnosis that includes other mycosis, tuberculosis, sarcoidosis, and primary skin cancers. ${ }^{11}$ Various pathologies are seen, but suppurative granulomas with double-walled spherules containing endospores are the most common. ${ }^{17}$ Organismfree reactive skin lesions are also seen, including erythema nodosum, reactive interstitial granulomatous dermatitis, erythema multiforme, and Sweet's syndrome. ${ }^{20}$ Painful red subcutaneous nodules of erythema nodosum typically develop 1-3 weeks after the symptoms arise ${ }^{21}$ and are thought to be the most prevalent reactive skin lesion of coccidioidomycosis. ${ }^{22}$ Erythema nodosum exhibits gender disparity in the setting of coccidioidomycosis, occurring more often in white females and rarely in African-American males. ${ }^{12}$ The presence of erythema nodosum is said to portend a favorable prognosis. ${ }^{19}$

Skin infections are also the most common manifestation of disseminated infection to the head and neck, although spread to deep tissues such as lymph nodes has been reported..$^{23}$ Lymphadenopathy of supraclavicular and cervical nodes may represent the only feature of infection in patients without primary pulmonary infection ${ }^{24}$ or evidence of disseminated disease ${ }^{25}$ or may occur as a result of direct lymphatic drainage of a primary pulmonary infection. ${ }^{26}$ Coccidioidal infection of other head and neck structures has been described, although with an ill-defined incidence and a paucity of case reports. ${ }^{23,24,27-32}$ The presence of splenomegaly attributed to coccidioidal infection in immunocompetent patients, as in our patient, is a rare occurrence. ${ }^{33}$

In the setting of symptomatic extrapulmonary infection such as in our patient, systemic antifungals provide optimal treatment, requiring at least 6 months and often years for eradication. ${ }^{2,25}$ The role of decreasing fungal load by needle aspiration or surgical debulking of enlarged lymph nodes is unclear ${ }^{25}$ and was not attempted in the treatment of the patient.

Our patient was immunocompetent and otherwise healthy save the bout of pneumonia. His African-American race was the only risk factor for disseminated coccidioidal disease. The differential diagnosis for lymphadenopathy and splenomegaly in the setting of constitutional symptoms such as weight loss includes malignancy and infectious etiologies such as tuberculosis. In fact, given our patient's history of smoking and incarceration, the suspicion for tuberculosis was high. However, the presence of adenopathy, especially supraclavicular lymphadenopathy, prompted tissue analysis that confirmed the diagnosis of coccidioidomycosis.

\section{Conclusion}

Coccidioidomycosis has long been christened the "great imitator," making the diagnosis rather cumbersome. Clinical suspicion should, therefore, be high in patients with risk factors, to ensure prompt diagnosis and treatment.

\section{Acknowledgment}

The patient provided written consent for patient details and accompanying images to be published.

\section{Disclosure}

The authors report no conflicts of interest in this work.

\section{References}

1. Chiller TM, Galgiani JN, Stevens DA. Coccidioidomycosis. Infect Dis Clin North Am. 2003;17(1):41-57.

2. Berg N, Ryscavage P, Kulesza P. The utility of fine needle aspiration for diagnosis of extrapulmonary coccidioidomycosis: a case report and discussion. Clin Med Res. 2011;9(3-4):130-133.

3. Parish JM, Blair JE. Coccidioidomycosis. Mayo Clin Proc. 2008;83(3): 343-349.

4. DiCaudo DJ. Coccidioidomycosis: a review and update. $J$ Am Acad Dermatol. 2006;55(6):929-942.

5. Murthy MH, Blair JE. Coccidioidomycosis. Curr Fungal Infect Rep. 2009;3(1):7-14.

6. Laniado-Laborín R. Coccidioidomycosis and other endemic mycoses in Mexico. Rev Iberoam Micol. 2007;24(4):249-258.

7. Centers for Disease Control and Prevention (CDC). Increase in reported coccidioidomycosis - United States, 1998-2011. MMWR Morb Mortal Wkly Rep. 2013;62(12):217-221.

8. Flaherman VJ. Estimating severe coccidioidomycosis in California. Emerg Infect Dis. 2007;13(7):1087-1090.

9. Rosenstein NE, Emery KW, Werner SB, et al. Risk factors for severe pulmonary and disseminated coccidioidomycosis: Kern County, California, 1995-1996. Clin Infect Dis. 2001;32(5):708-714.

10. Durry E, Pappagianis D, Werner SB, et al. Coccidioidomycosis in Tulare County, California, 1991: reemergence of an endemic disease. $J$ Med Vet Mycol. 1997;35(5):321-326.

11. Crum NF, Lederman ER, Stafford CM, Parrish JS, Wallace MR. Coccidioidomycosis: a descriptive survey of a reemerging disease. Clinical characteristics and current controversies. Medicine (Baltimore). 2004;83(3):149-175.

12. Smith CE, Beard RR. Varieties of coccidioidal infection in relation to the epidemiology and control of the diseases. Am J Public Health Nations Health. 1946;36(12):1394-1402.

13. Hobbs ER. Coccidioidomycosis. Dermatol Clin. 1989;7(2):227-239.

14. Quimby SR, Connolly SM, Winkelmann RK, Smilack JD. Clinicopathologic spectrum of specific cutaneous lesions of disseminated coccidioidomycosis. J Am Acad Dermatol. 1992;26(1):79-85.

15. Welsh O, Vera-Cabrera L, Rendon A, Gonzalez G, Bonifaz A. Coccidioidomycosis. Clin Dermatol. 2012;30(6):573-591. 
16. Forbus WD, Bestebreurtje AM. Coccidioidomycosis: a study of 95 gases of the disseminated type with special reference to the pathogenesis of the disease. Mil Surg. 1946;99(5):653-719.

17. Carpenter JB, Feldman JS, Leyva WH, DiCaudo DJ. Clinical and pathologic characteristics of disseminated cutaneous coccidioidomycosis. $J$ Am Acad Dermatol. 2010;62(5):831-837.

18. Schwartz RA, Lamberts RJ. Isolated nodular cutaneous coccidioidomycosis: the initial manifestation of disseminated disease. $J$ Am Acad Dermatol. 1981;4(1):38-46.

19. Arsura EL, Kilgore WB, Caldwell JW, Freeman JC, Einstein HE, Johnson RH. Association between facial cutaneous coccidioidomycosis and meningitis. West J Med. 1998;169(1):13-16.

20. DiCaudo DJ, Connolly SM. Interstitial granulomatous dermatitis associated with pulmonary coccidioidomycosis. J Am Acad Dermatol. 2001;45(6):840-845.

21. Smith CE. Epidemiology of acute coccidioidomycosis with erythema nodosum ("San Joaquin" or "Valley Fever"). Am J Public Health Nations Health. 1940;30(6):600-611.

22. Drutz DJ, Catanzaro A. Coccidioidomycosis: part II 1, 2. Am Rev Respir Dis. 1978;117(4):727-771.

23. Copeland B, White D, Buenting J. Imaging case study of the month coccidioidomycosis of the head and neck. Ann Otol Rhinol Laryngol. 2003;112(1):98-101.

24. Dudley JE. Coccidioidomycosis and neck mass "single lesion" disseminated disease. Arch Otolaryngol Head Neck Surg. 1987;113(5): $553-555$.
25. Biller JA, Scheuller MC, Eisele DW. Coccidioidomycosis causing massive cervical lymphadenopathy. Laryngoscope. 2004;114(11):1892-1894.

26. Galgiani JN. Coccidioidomycosis (Coccidioides species). Mandell, Douglas, and Bennett's Principles and Practice of Infectious Diseases. 2014;2:2974-2984.

27. Loudin M, Clayburgh DR, Hakki M. Coccidioides immitis cervical lymphadenitis complicated by esophageal fistula. Case Rep Infect Dis. 2016;2016:8715405.

28. D'Avino A, Di Giambenedetto S, Fabbiani M, Farina S. Coccidioidomycosis of cervical lymph nodes in an HIV-infected patient with immunologic reconstitution on potent HAART: a rare observation in a nonendemic area. Diagn Microbiol Infect Dis. 2012;72(2):185-187.

29. Hicks MJ, Green LK, Clarridge J. Primary diagnosis of disseminated coccidioidomycosis by fine needle aspiration of a neck mass. A case report. Acta Cytol. 1993;38(3):422-426.

30. Kafka JA, Catanzaro A. Disseminated coccidioidomycosis in children. J Pediatr. 1981;98(3):355-361.

31. Mathew G, Smedema M, Wheat LJ, Goldman M. Relapse of coccidioidomycosis despite immune reconstitution after fluconazole secondary prophylaxis in a patient with AIDS. Mycoses. 2003;46(1-2):42-44.

32. Newland Y, Komisar A. Coccidioidomycosis of the head and neck. Ear Nose Throat J. 1986;65(10):473-477.

33. Bird GR, Libke RD, Billelo JF, Parks NA, Pollard JS. Disseminated coccidioidomycosis with clinically evident splenomegaly in an immunocompetent host, first case reported in the literature. Mcgill J Med. 2009;12(2):14.
International Medical Case Reports Journal

\section{Publish your work in this journal}

The International Medical Case Reports Journal is an international, peer-reviewed open-access journal publishing original case reports from all medical specialties. Previously unpublished medical posters are also accepted relating to any area of clinical or preclinical science. Submissions should not normally exceed 2,000 words or
Submit your manuscript here: https://www.dovepress.com/international-medical-case-reports-journal-journal
4 published pages including figures, diagrams and references. The manuscript management system is completely online and includes a very quick and fair peer-review system, which is all easy to use. Visit http://www.dovepress.com/testimonials.php to read real quotes from published authors. 